\title{
Lesión renal aguda secundaria a lisis tumoral inducida por esteroides en una adolescente con leucemia linfoblástica aguda. Rol de la alcalinización urinaria y diálisis peritoneal Acute kidney injury secondary to steroid-induced tumor lysis in an adolescent with acute lymphoblastic leukemia. Role of urinary alkalinisation and peritoneal dialysis
}

\author{
Dr. Gustavo Roberto Marín ${ }^{a}$ y Dra. Elena Majek
}

\section{RESUMEN}

Una adolescente con leucemia linfoblástica aguda desarrolló un síndrome de lisis tumoral precoz y grave con lesión renal aguda luego de una dosis única y baja de esteroides. La disfunción renal se atribuyó primariamente a una nefropatía por fosfato con nefrocalcinosis debido a elevaciones extremas de este componente en sangre. La alcalinización urinaria probablemente contribuyó a su patogenia. Se utilizó diálisis peritoneal con resolución de la nefrocalcinosis y normalización de la depuración de creatinina.

Palabras clave: lisis tumoral, lesión renal aguda, leucemia, fosfato.

\section{SUMMARY}

An adolescent with acute lymphoblastic leukemia developed an early and severe tumor lysis syndrome with acute kidney injury after a low and single dose of steroids. Renal dysfunction was attributed primarily to phosphate nephropathy with nephrocalcinosis due to extreme elevations of phosphate in blood. Urinary alkalinization probably contributed to this development. We used peritoneal dialysis with resolution of nephrocalcinosis and normalization of creatinine clearance. Key words: Tumor lysis, acute kidney injury, leukemia, phosphate.

http:/ /dx.doi.org/10.5546/aap.2012.e118

\section{INTRODUCCIÓN}

El síndrome de lisis tumoral (SLT) es una emergencia oncológica causado por la destrucción de células neoplásicas que cursa con hiperuricemia, hiperpotasemia, hiperfosfatemia e hipocalcemia secundaria. Por lo general, suele manifestarse luego de $48 \mathrm{~h}$ de iniciada la terapia antineoplásica o, más raramente, de manera espontánea.

\footnotetext{
a. Unidad de Nefrología

b. Unidad de Oncohematología.

Hospital de Niños "Héctor Quintana", Jujuy. Argentina.

Correspondencia:

Dr. Gustavo Roberto Marín: tama@imagine.com.ar
}

Conflicto de intereses: Ninguno que declarar.

Recibido: 7-5-2012

Aceptado: 29-6-2012
Las neoplasias hematológicas son la causa principal, rara vez un tumor sólido. La complicación más frecuente suele ser una lesión renal aguda (LRA). Los factores de riesgo más significativos que predisponen al desarrollo del SLT y la LRA se detallan en el Cuadro $1 .^{1-7}$ Describimos el caso de una adolescente con leucemia linfoblástica aguda (LLA-B) tratada con esteroides, que desarrolló una lisis tumoral precoz y grave con LRA y nefrocalcinosis que requirió diálisis peritoneal para su recuperación. Analizamos las medidas terapéuticas del caso y su relación con la evolución de la paciente.

\section{CASO CLÍNICO}

Paciente de 12 años de vida con cuadro clínico de dos semanas de evolución caracterizado por astenia, epistaxis y deposiciones sanguinolentas. Ingresó eutrófica, normohidratada, normotensa con leve taquicardia, se evidenciaron adenopatías submaxilares bilaterales, laterocervicales y supraclaviculares izquierdas dolorosas a la palpación, epistaxis bilateral, hematomas en resolución en miembros inferiores, petequias en paladar blando y hepatoesplenomegalia indolora. La evo-

Cuadro 1. Factores de riesgo más relevantes para el desarrollo de lisis tumoral y lesión renal

- Compromiso renal o de vía urinaria preexistente

- Deshidratación/hipovolemia*

- Infiltración masiva de órganos abdominales y médula ósea*

- Leucemia linfoblástica aguda*

- Linfoma de Burkitt

- Hiperuricemia preexistente

- Gran carga tumoral*

- Láctico deshidrogenasa > doble del valor normal

- Recuento de leucocitos $>50000 \mathrm{~mm}^{3}$

- Quimioterapia inicial intensa

- Tumor muy proliferativo*

- Tumor altamente sensible a terapia citorreductora*

* Presentes en nuestro caso. 
lución del laboratorio se muestra en Tabla 1. La radiografía de tórax y ecografía renal fueron normales (RD 9,8 cm, RI 10,2 cm). Se indicó hidratación con solución salina a $3 \mathrm{~L} / \mathrm{m}^{2}$, bicarbonato de sodio a $50 \mathrm{mEq} / \mathrm{L}$, allopurinol, furosemida, cinco unidades de plaquetas, calcio oral, antiácidos; se le realizó taponamiento nasal anterior; la diuresis promedió $1,5 \mathrm{~cm}^{3} / \mathrm{kg} / \mathrm{h}$. Una punción de médula ósea evidenció infiltración con blastos en un $90 \%$. Se diagnosticó leucemia linfoblástica aguda de tipo B (pre B) BCR-ABL 190 positivo. Mantuvo algunas deposiciones sanguinolentas sin alteración hemodinámica. Al sexto día de internación se indicó metilprednisolona $30 \mathrm{mg}$ cada 12 h (15 mg/ $\mathrm{m}^{2} / \mathrm{d}$ ). Doce horas después presentó abundantes deposiciones sanguinolentas, la diuresis descendió a $0,4 \mathrm{~cm}^{3} / \mathrm{kg} / \mathrm{h}$. Se indicó dos expansiones con solución fisiológica, 2 unidades de glóbulos rojos sedimentados y 5 de plaquetas; se suspendió la alcalinización urinaria, el calcio y la furosemida; continuó con metilprednisolona $25 \mathrm{mg}$ / día. Horas después ingresó a terapia intensiva, hipotensa con sensorio obnubilado y diátesis hemorrágica grave; recibió 4 expansiones con solución fisiológica, dos unidades de glóbulos rojos y cinco de plaquetas; recuperó diuresis normal. Una ecografía renal evidenció nefromegalia bilateral: riñón derecho 11,9 cm; izquierdo $13 \mathrm{~cm}$; (P95 para talla: $10,5 \mathrm{~cm})$, nefrocalcinosis e imagen litiásica en seno renal derecho (Figura $1 A, B, C$ ). Inició asistencia respiratoria mecánica, recibió gluconato cálcico más betabloqueante para la hiperpotasemia y diálisis peritoneal previa transfusión con $500 \mathrm{~cm}^{3}$ de plasma, 5 unidades de plaquetas y 2

Tabla 1. Días de internación

\begin{tabular}{|c|c|c|c|c|c|c|c|}
\hline Laboratorio & Ingreso & $\begin{array}{c}\text { 6to. } \\
\text { pre esteroides }\end{array}$ & $\begin{array}{c}\text { 6to. } \\
12 \mathrm{~h} \text { pos esteroides }\end{array}$ & $\begin{array}{l}7 \mathrm{mo} . \\
\text { prediálisis }\end{array}$ & $\begin{array}{l}\text { 9no. } \\
\text { diálisis }\end{array}$ & $\begin{array}{l}\text { 11mo. } \\
\text { diálisis }\end{array}$ & $\begin{array}{c}48 \mathrm{~h} \\
\text { posdiálisis }\end{array}$ \\
\hline Hematócrito & $26 \%$ & & $18 \%$ & $15 \%$ & & & \\
\hline Leucocitos & $\begin{array}{c}60000 \mathrm{~mm}^{3} \\
(95 \% \text { blastos})\end{array}$ & 140000 & & & & & \\
\hline Plaquetas & $23000 \mathrm{~mm}^{3}$ & & 12000 & $8000 \mathrm{~mm}^{3}$ & & & \\
\hline Tiempo protrombina & $13,7 \mathrm{seg}$. & & & & & & \\
\hline $\mathrm{APP}$ & $75 \%$ & & & & & & \\
\hline Creatininemia & $\begin{array}{c}1,1 \mathrm{mg} / \mathrm{dl} \\
(\mathrm{vn}: 0,7-1,4 \mathrm{mg} / \mathrm{dl})\end{array}$ & 1,2 & 3,06 & 6,2 & & & 3,8 \\
\hline Uremia & $33 \mathrm{mg} / \mathrm{dl}$ & & 147 & & & & \\
\hline Uricemia & $4,2 \mathrm{mg} / \mathrm{dl}$ & 4,5 & 10,6 & 21 & & & 14 \\
\hline Fosfatemia & $3,2 \mathrm{mg} / \mathrm{dl}$ & 4,4 & 21,2 (dos registros) & 25,2 & 18,8 & 12,9 & 8,9 \\
\hline Calcemia & $8,2 \mathrm{mg} / \mathrm{dl}$ & 9,2 & 4,9 & 5 & & & 8 \\
\hline Magnesemia & $1,5 \mathrm{mg} / \mathrm{dl}$ & & & & & & \\
\hline Transaminasa GP/GO & $20 / 18 \mathrm{UI} / \mathrm{L}$ & & & & & & \\
\hline $\mathrm{LDH}$ & & $\begin{array}{c}2040 \mathrm{U} / \mathrm{L} \\
\text { (vn: } 150-300 \mathrm{U} / \mathrm{L})\end{array}$ & 3157 & & & & \\
\hline \multicolumn{8}{|l|}{ Ionograma sangre } \\
\hline $\mathrm{Na}-\mathrm{K}-\mathrm{Cl}$ & $137-4,2-103 \mathrm{mEq} / \mathrm{L}$ & & $129-6-97$ & $125-6,7-93$ & & & \\
\hline Bicarbonatemia & $19 \mathrm{mEq} / \mathrm{L}$ & & & 12 & & & \\
\hline Orina completa & normal & $\begin{array}{c}\text { normal, pH } 7 \\
\text { densidad 1010-1015 }\end{array}$ & $\begin{array}{c}\text { hematuria, cristales } \\
\text { urato amonio }\end{array}$ & $\begin{array}{l}\text { hematuria } \\
\text { proteinuria }\end{array}$ & & & \\
\hline Uricosuria & & & $18 \mathrm{mg} / \mathrm{dl}$ & 84 & & & \\
\hline Fosfaturia & & & $83 \mathrm{mg} / \mathrm{dl}$ & 93 & & & \\
\hline $\begin{array}{l}\text { Ácido úrico/ } \\
\text { creatinina orina }\end{array}$ & & & $\begin{array}{c}1,02 \\
\text { (> } 1 \text { LRA por uratos) }\end{array}$ & 4,5 & & & \\
\hline $\begin{array}{l}\text { Reabsorción } \\
\text { tubular fosfato }\end{array}$ & & & $<20 \%(\mathrm{vn}:>80 \%)$ & & & & \\
\hline Calciuria & & & & $1,1 \mathrm{mg} / \mathrm{dl}$ & & & \\
\hline Proteinuria & & & & $220 \mathrm{mg} / \mathrm{dl}$ & & & \\
\hline Creatininuria & & & & $18,4 \mathrm{mg} / \mathrm{dl}$ & & & \\
\hline
\end{tabular}

APP: porcentaje de actividad de protombina. 
de glóbulos rojos. La diálisis fue continua, baños de 1 hora de permanencia, solución al 2,5\%, volumen por baño de $1200 \mathrm{~cm}^{3} / \mathrm{m}^{2}$. Posimplantación de catéter recibió $500 \mathrm{~cm}^{3}$ de plasma y 5 unidades de plaquetas por sangrado peritoneal. Junto con el descenso de la fosfatemia la paciente presentó franca mejoría del sensorio, tensión arterial y coagulación. Se dializó 10 días con diuresis normal. Posteriormente, se realizó tratamiento según protocolo GATLA-LLA_Filadelfia positivo. Un mes después, los resultados de laboratorio y ecografía renal fueron normales (Figura $1 D, E$ ).

FIgURA 1. A-B: Ecografía longitudinal riñón derecho (A) e izquierdo (B). Nefromegalia y aumento de ecogenicidad bilateral. Papilas refringentes, nefrocalcinosis. C: Ecografía transversal riñón derecho. Litiasis en seno. D-E: Ecografía longitudinal riñón derecho $(D)$ e izquierdo $(E)$. Aspecto normal un mes posterior a imágenes anteriores
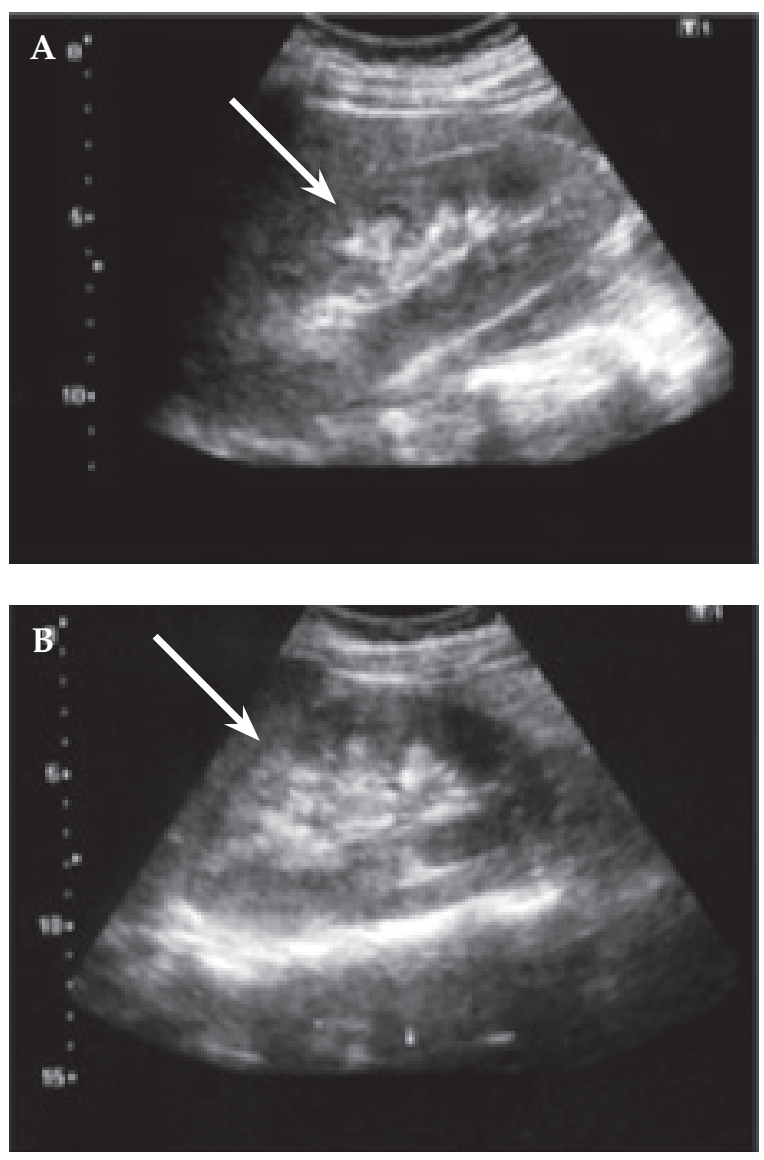
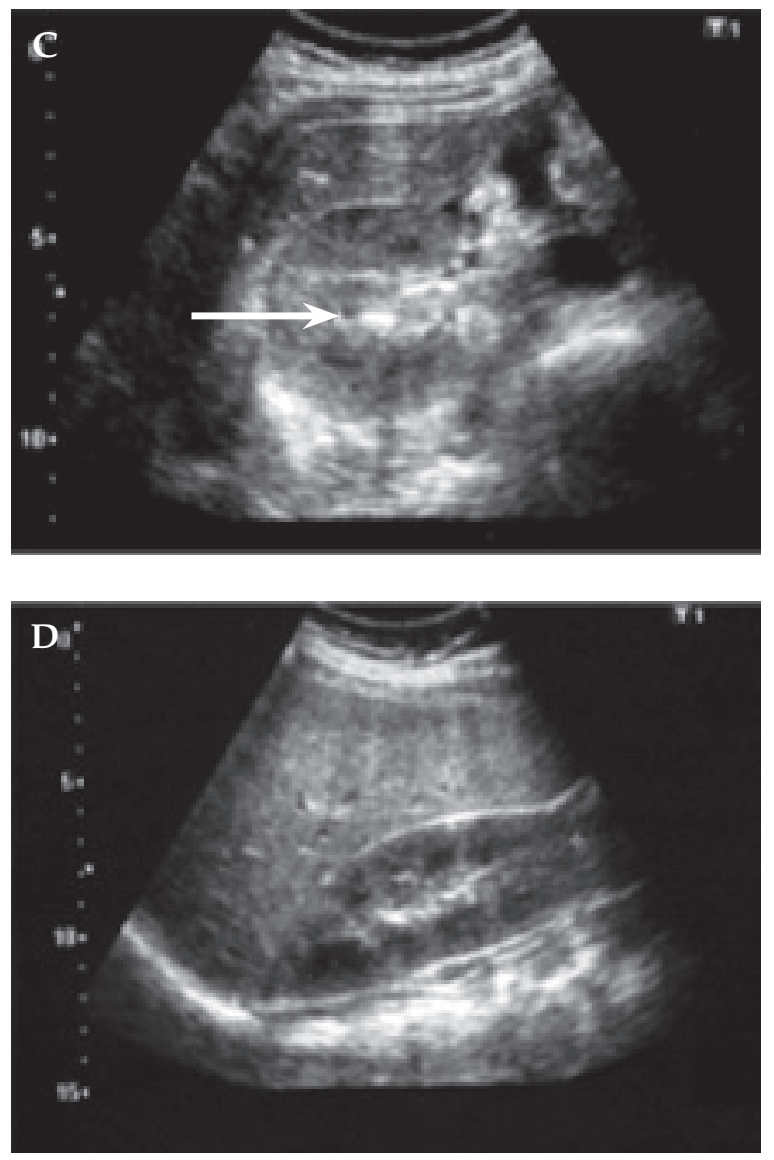

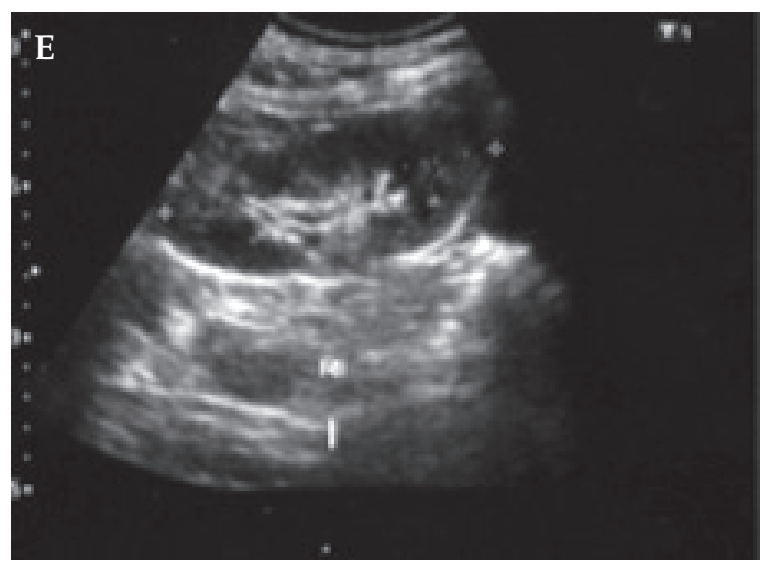




\section{DISCUSIÓN}

Entre las neoplasias hematológicas, la LLA-B presenta la incidencia más elevada de SLT y LRA, esta última oscila en $11-45 \% .^{2-4,7}$

Es causada principalmente por:

1. precipitación tubular de cristales de ácido úrico y fosfocálcicos (rara vez xantina) en el nefrón distal que genera obstrucción, inflamación regional y sistémica y

2. alteraciones del flujo renal con isquemia. ${ }^{1-5}$

Otras causas posibles de LRA en un paciente oncológico se detallan en el Cuadro 2. El tratamiento profiláctico de un SLT tradicionalmente ha consistido en el uso de hiperhidratación, allopurinol y alcalinización urinaria. La hidratación intensiva para lograr un flujo urinario poliúrico es el factor más importante en la profilaxis de la LRA. El allopurinol bloquea la formación de ácido úrico, pero aumenta su precursor xantina, que puede cristalizar. La alcalinización urinaria favorece la excreción de uratos haciéndolos más solubles, pero pueden precipitarse cristales fosfocálcicos y causar LRA. Recientemente se agregó rasburicasa como fármaco antiuricémico más eficaz debido a que transforma el ácido úrico en alantoína, sustancia soluble en orina independientemente del $\mathrm{pH} .{ }^{8}$ Esta variante terapeútica ha desplazando el uso de la alcalinización urinaria por los riesgos que implica. ${ }^{1,2,46} \mathrm{Al}$ no disponer de rasburicasa, nuestra paciente, categorizada como de alto riesgo, recibió quimioprofilaxis según lineamientos convencionales. Desarrolló un síndrome de lisis tumoral grave y precoz (en $12 \mathrm{~h}$ ) luego de una dosis baja (30 mg) y única de metilprednisolona.

Como el síndrome habitualmente sigue a un protocolo con fármacos combinados, esta respuesta es infrecuente, con pocos casos descriptos en la

Cuadro 2. Causas de lesión renal aguda en pacientes neoplásicos

- Nefropatía por cristales (ácido úrico, fosfocálcicos, purinas)

- Infiltración parenquimatosa tumoral

- Necrosis tubular aguda por hipovolemia

- Sepsis-coagulación intravascular diseminada

- Pielonefritis aguda

- Nefritis tubulointersticial por fármacos

- Nefropatía por contraste

- Glomerulopatía asociada

- Microangiopatía trombocitopénica trombótica

- Uropatía obstructiva litiásica-tumoral

- Infiltración vascular tumoral bibliografía que recibieron dosis más altas de metilprednisolona (intervalo 95-2000 mg); una gran carga tumoral parece ser un factor predisponente, dato clínico presente en nuestra paciente. ${ }^{9}$

Pensamos que la causa inicial de la LRA en nuestro caso fue una nefropatía por fosfatos por la extrema elevación de la fosfatemia previo a un ascenso significativo de la uricemia, lo que llevó el producto fosfocálcico a 126 (máximo de solubilidad estimado de $58 \mathrm{mg}$ ) produciéndose una nefrocalcinosis con litiasis; casos similares se describen en la bibliografía con diuresis variable. ${ }^{10-12}$ Una nefropatía por uratos posteriormente contribuyó al daño renal, ya que se registró una relación urinaria ácido úrico/creatinina de 4,5 (<0,75 en otras causas de fallo renal). ${ }^{4} \mathrm{La}$ alcalinización llevó el pH urinario a 7, lo cual probablemente favoreció la nefropatía por fosfato y no evitó la nefropatía por uratos.

Nuestra paciente presentó un episodio de hipovolemia aguda con oliguria, recibió varias expansiones y recuperó una diuresis normal, pero no fue posible incrementarla en gama poliúrica, quizás, por su diátesis hemorrágica difícil de compensar, lo que probablemente contribuyó al depósito de cristales, todo lo cual refuerza la importancia de un alto flujo urinario como la mejor profilaxis y revela la dudosa utilidad de una orina alcalina. Tambien presentó nefromegalia bilateral; una LRA por cristales podría causarla por el proceso inflamatorio asociado, también una infiltración tumoral con compromiso gomerular o sin él. Una biopsia renal habría ayudado a clarificar más el diagnóstico dada la presencia de proteinuria nefrótica, pero la coagulopatía de la paciente la contraindicó. La infiltración tumoral es común en la LLA-B, pero rara vez produce nefromegalia (24\%) y menos aún fallo renal $(<1 \%) .{ }^{13}$

Nuestra paciente mejoró su creatininemia con diálisis incluso antes de comenzar un protocolo de inducción y su proteinuria fue transitoria, por lo que suponemos no tuvo infiltración clínicamente significativa. La necesidad de terapia de reemplazo renal ha sido comunicada en un 3-59\%. ${ }^{4} \mathrm{La}$ hemodiálisis y hemofiltración con sus variantes han demostrado ser superiores en la remoción de fosfato y ácido úrico en relación a la diálisis peritoneal, de poco uso en la actualidad; sin embargo, se requieren recursos técnicos apropiados y un acceso vascular, lo cual es un riesgo en pacientes con diátesis hemorrágica grave, como en nuestro caso. ${ }^{1-5,14}$ Debido a estas limitaciones utilizamos diálisis peritoneal diaria, continua, con grandes volúmenes de solución dializante; como 
la paciente mantuvo diuresis normal (mayor depuración de fosfato-uratos) se logró evitar a corto plazo un daño renal mayor con desaparición de la nefrocalcinosis y normalización del filtrado glomerular, evolución descripta en casos similares..$^{3,12,14,15}$ Resta determinar el impacto a largo plazo por el riesgo de enfermedad renal crónica inducida por fosfatos.

En conclusión:

1. un síndrome de lisis tumoral grave puede aparecer precozmente luego de una dosis baja de esteroides, por lo cual, es obligatorio un monitoreo frecuente de laboratorio;

2. la alcalinización urinaria es de dudosa utilidad para prevenir una nefropatía por uratos y parece favorecer la de fosfatos, por lo cual, lineamientos recientes no la recomiendan, ${ }^{2,6,8}$ la diálisis peritoneal permite evitar un daño renal mayor si no se dispone de otras modalidades dialíticas o están contraindicadas.

\section{BIBLIOGRAFÍA}

1. Howard SC, Jones DP, Hon Pui CH. The tumor lysis syndrome. N Engl J Med 2011;364:1844-54.

2. Mughal T, Ejaz AA, Foringer JR, Coiffier B. An integrated clinical approach for the identification, prevention, and treatment of tumor lysis syndrome. Cancer Treatment Reviews 2010;36:164-76.

3. Davidson MB, Thakkar S, Hix JK, Bhandarkar ND, et al. Pathophysiology, clinical consequences, and treatment of tumor lysis syndrome. Am J Med 2004;116:546-54.

4. Abu-Alfa AK, Younes A. Tumor lysis syndrome and Acute kidney injury: evaluation, prevention, and management. Am J Kidney Dis 2010;55(S3):S1-S13.
5. Jones DP, Mahmoud H, Chesney RW. Tumor lysis syndrome: pathogenesis and management. Pediatr Nephrol 1995;9:206-12.

6. Comité Nacional de Hematología-Sociedad Argentina de Pediatría. Guía para el manejo clínico del síndrome de lisis tumoral agudo. Arch Argent Pediatr 2011;109:77-82.

7. Wössmann W, Schrappe M, Meyer U, Zimmermann M, et al. Incidence of tumor lysis syndrome in children with advanced stage Burkitts lymphoma/leukemia before and after introduction of prophylactic use of urate oxidase. Ann Hematol 2003;82:160-5.

8. Cairo MS, Coiffier B, Reiter A, Younes A. Recommendations for the evaluation of risk and prophylaxis of tumour lysis syndrome (TLS) in adults and children with malignant diseases: an expert TLS panel consensus. Br J Haematol 2010;149:578-86.

9. Duzova A, Cetin M, Gümrük F, Yetgin S. Acute tumour lysis syndrome following a single-dose corticosteroid in children with acute lymphoblastic leukaemia. Eur J Haematol 2001;66:404-7.

10. Haas M, Ölher L, Watzke H, Bömig H, et al. The spectrum of acute renal failure in tumor lysis syndrome. Nephrol Dial Transplant 1999;14:776-9.

11. Boles JM, Dutel JL, Briere J, Mialon P, et al. Acute renal failure caused by extreme hyperphosphatemia after chemotherapy of an acute lymphoblastic leukemia. Cancer 1984;53:2425-9.

12. Ettinger DS, Harker WG, Gerry HW, Sanders RC, et al. Hyperphosphatemia, hypocalcemia, and transient renal failure results of cytotoxic treatment of acute lymphoblastic leukemia. JAMA 1978;239:2472-4.

13. Pradee R, MadhumathiDS, Lakshmidevi V, Premalata ChS. et al. Bilateral nephromegaly simulating Wilms tumor a rare initial manifestation of acutelymphoblastic leukemia. J Pediatr Hematol Oncol 2008;30:471-3.

14. Kuhlmann MK. Phosphate elimination in modalities of hemodialysis and peritoneal dialysis. Blood Purif2010;29:137-44.

15. Wechsler DS, Kastan M, Fivush B. Resolution of nephrocalcinosis associated with tumor lysis syndrome. Pediatr Hematol Oncol 1994;11:115-1. 